\title{
Influence of Fatigue Strength for Electron Beam Weld Joint with Thin Steel Plate*
}

\begin{abstract}
by Takuya Nagai**, Ryu Kasai**, Kunika Ueno***, Masahito Mochizuki**** and Tetsuo Suga*****
Residual stress, considered to be an influential factor in fatigue strength, was investigated through X-ray stress measurements on electron-beam welding joints, made of sheet metal with a thickness of approximately $10 \mathrm{~mm}$. The Finite-Element Method (FEM) was also used to analyze the experimental results so as to verify any residual stress characteristics. The residual stress near the weld toe in the transverse direction was confirmed to be greatly compressed when the yield strength of the testing material became much greater. As a result of the three-point bending fatigue tests, except for S50C, it was demonstrated that the greater the residual stress of the test specimens was, the more they exhibited a longer fatigue life. It is thought that the reason for this was because the local area of the welded part became a stress concentration point due to its being greatly hardened.
\end{abstract}

Key Words: Electoron beam welding, Residual stress, Fatigue strength, X-ray diffraction method, Finite element method, Steel type

\section{Introduction}

Residual stresses in weld joints significantly affect the fatigue strength and stress-corrosion-crack resistance of the weld joint, and therefore, numerous studies have been made ${ }^{1)}$. Residual stresses induced by electron beam welding (EBW) have also been researched in various approaches ${ }^{2-3)}$; however, many of the research papers are associated with thick plates (with a thickness of $50 \mathrm{~mm}$ or more). This was because the EBW process was costly and thus studied on cost-effective thick plate components for such specific applications as observed in the nuclear-power and space-related fields that required extremely high qualities for the weldments.

In recent years, however, there have been many cases where the EBW process is employed in such general applications as autos, electric machines, and industrial tools. This is owing to reduction in the processing cost through usage expansion of the equipment and job shop's corporate efforts. In particular, EBW is applied for partial penetration welding of parts with a plate thickness of 3-15 $\mathrm{mm}$ as observed in car gears and gauge diaphragms. While EBW has been expanded in sheet metal applications, there are little reports of in-depth research on this field. Taking this into consideration, the authors have researched the residual stress characteristics in the partial penetration EBW welds of sheet metals.

The authors also reported the effects of welding conditions on residual stresses ${ }^{4)}$, in which it was clarified that weld penetration

\footnotetext{
${ }^{*}$ Received: 2014.11.28

${ }^{* *}$ Member, Shinko Welding Service Co., Ltd. (Kobe Steel Group)

*** Member, Tosei Electrobeam Co., Ltd.

${ }^{* * * *}$ Member, Graduate,School of Engineering, Osaka University

${ }^{* * * * *}$ Member, Joining and Welding Research Institute, Osaka University
}

influenced the extent of residual stress in the transverse direction to the weld axis at the weld toes that largely affected the fatigue strength. In the present report, the residual stress characteristics will be discussed in relationship to various steel grades tested under the constant welding conditions. Moreover, the present report provides the results of actual fatigue tests and discusses how they are affected by the residual stress.

\section{Experimental procedure}

For the testing materials, five kinds of steel plates (SS400, SUS304, HT60, S50C, and SCM440) having a thickness of 10 $\mathrm{mm}$, a width of $100 \mathrm{~mm}$, and a length of $100 \mathrm{~mm}$ were used. On these plates, bead-on-plate welding was conducted by using a 6-kW EBW machine. The welding conditions were kept constant as shown in Table 1 for all kinds of steel in order to compare the effects of varieties of steel. Also, the temperature history associated with welding was measured with thermocouples set on the face and back of the steel plate.

Table 1 Welding condition

\begin{tabular}{|c|c|c|c|c|c|}
\hline Test No. & 1 & 2 & 3 & 4 & 5 \\
\hline Steel grade & SS400 & SUS304 & HT60 & S50C & SCM440 \\
\hline Beam power & \multicolumn{5}{|c|}{$1200 \mathrm{~W}$} \\
\hline Beam diameter & \multicolumn{5}{|c|}{$500 \mathrm{~mm} / \mathrm{min}$} \\
\hline Weld speed & \multicolumn{5}{|c|}{} \\
\hline
\end{tabular}

Residual stresses were measured by the X-ray diffraction method. The measurement of residual stress was conducted under the conditions shown in Table 2 according to the Standard for $\mathrm{X}$-ray Stress Measurement ${ }^{5)}$.The residual stresses along the direction perpendicular to the weld axis were measured for 
assessment at points of 1-mm intervals in the range of 0.5-6.5 mm from the weld toe. The measuring surface was treated by electrochemical polishing to eliminate the effect of the surface processing strain.

Table 2 Condition of X-ray

\begin{tabular}{|c|c|c|}
\hline \multicolumn{4}{|c|}{ stress measurement } \\
\hline Steel grade & SUS304 & Others \\
\hline Characteristic X-ray & $\mathrm{Cr}-\mathrm{K} \beta$ & $\mathrm{Cr}-\mathrm{K} \alpha$ \\
\hline Diffraction plane & $(311)$ & $(211)$ \\
\hline X-ray stress constant & $-366 \mathrm{MPa} / \mathrm{deg}$ & $-318 \mathrm{MPa} / \mathrm{deg}$ \\
\hline Collimator diameter & \multicolumn{3}{|c|}{$1.0 \mathrm{~mm} \varphi$} \\
\hline
\end{tabular}

The FEM analysis was also carried out to confirm the adequacy of residual stress measurements. For the analytical model the three-dimension model with $20 \mathrm{~mm}$ in the longitudinal direction and the right-left symmetric $1 / 2$ part with respect to the weld axis, as shown in Fig.1, was adopted in order to shorten the time for computation.

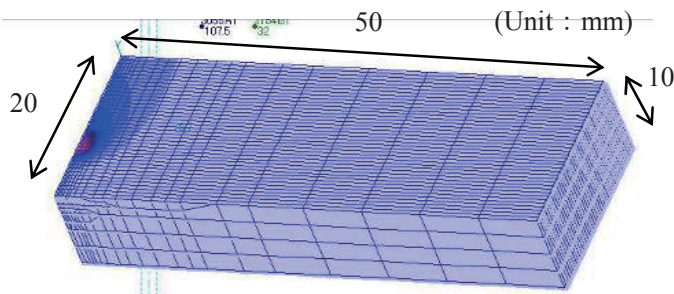

Fig. 1 FEM model

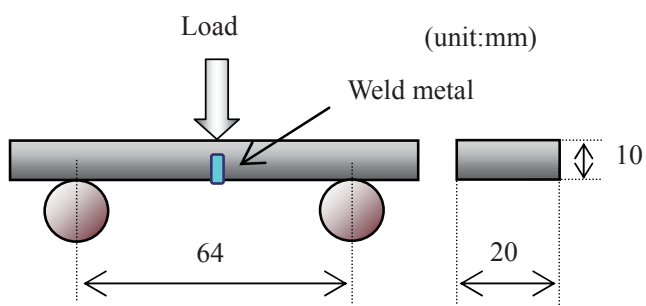

Fig. 2 Outline of fatigue test

The fatigue test specimen with a width of $20 \mathrm{~mm}$ was machine

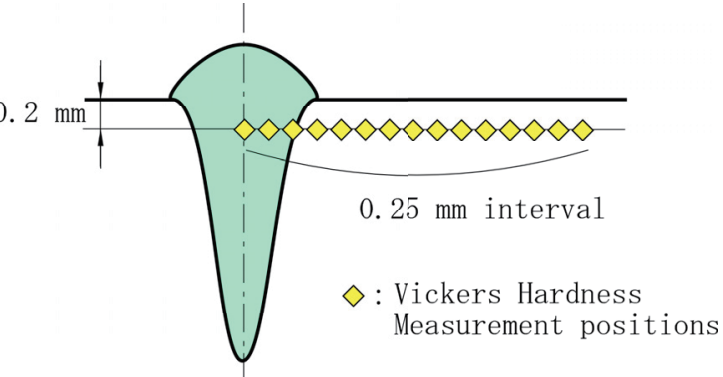

Fig. 3 Vickers Hardness Measurement positions cut from the central area of the above-mentioned bead-on-plate weld coupon and was tested under the three-point bending load (Fig. 2). Fatigue test was conducted in the load control mode with a stress ratio of 0.1 and a frequency of $15 \mathrm{~Hz}$, and the stress ranges were 405 and $540 \mathrm{MPa}$.

Vickers hardness test was carried out at approx. $0.2 \mathrm{~mm}$ below the surface of the test specimen, under a testing load of 300 gf. Measurement positions are shown in Fig. 3.

\section{Experimental results and discussions}

\subsection{Residual stresses}

Cross-sectional macrographs of welds are shown in Fig.4. Since welding condition was kept constant, penetration depth and bead width resulted in similar measurements fo all the testing materials. The FEM analysis model was made based on these macrographs.

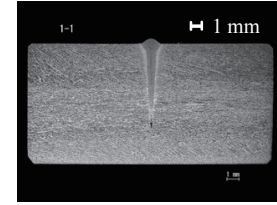

(a)SS400

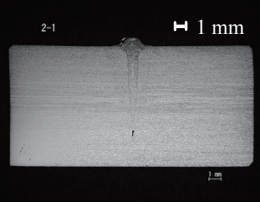

(b)SUS304

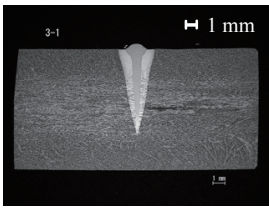

(c)S50C

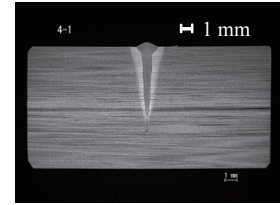

(d)HT60

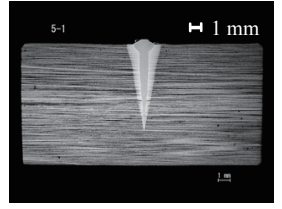

(e)SCM440
Fig. 4 Macrostructure

The measurement result of the residual stress in the normal direction to the weld axis is shown in Fig. 5(a). In Fig. 5(b), the analysis result of the residual stress is shown, in which the stress values exhibit the similar tendency to the experimental stress values. Compressive residual stresses are observed near the weld toe, and the become zero as the measuring point departs from the weld toe. There is a comparatively large difference especially near the weld toe; this is probably because the stress inclination at the area near the weld toe is larger. The residual stress obtained by measurement is the average value of the X-ray irradiated area of $1 \mathrm{~mm} \Phi$. Good agreement can be observed in the part where the inclination is smaller. From the above facts, the analytical results can be deemed usable. Since the residual stress near the weld toe is more important and the heat 


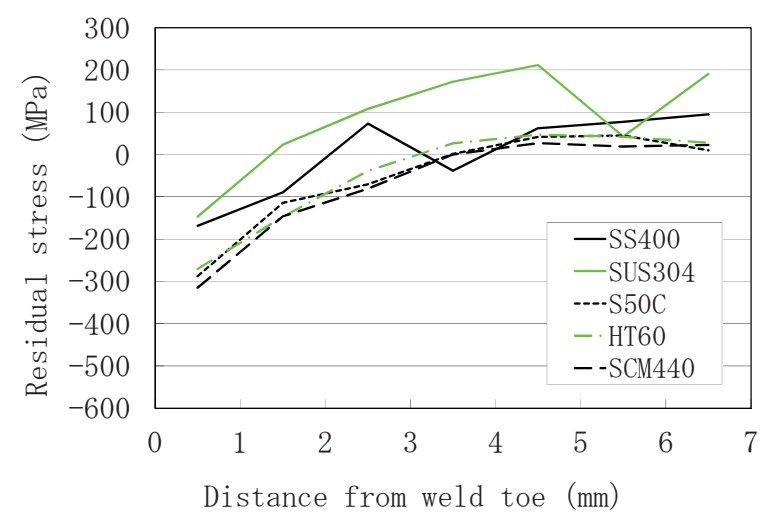

(a) Measurement results

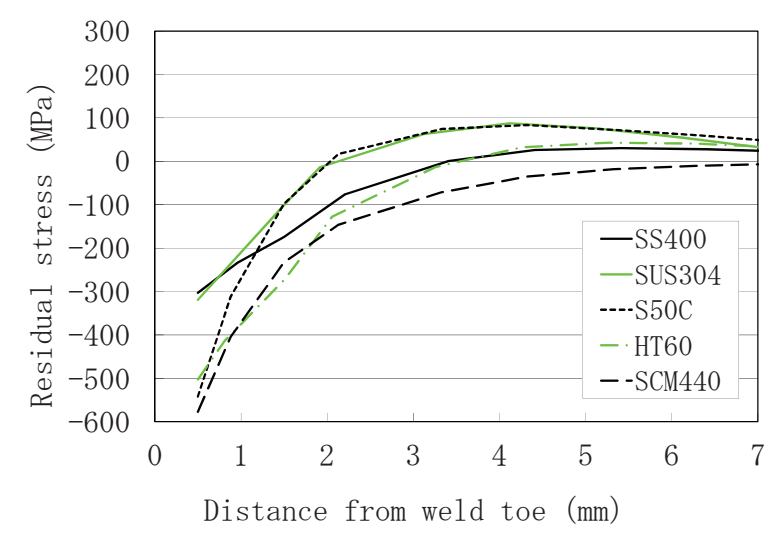

(b) Analysis results

Fig. 5 Residual stress distribution

conduction of the analytical model almost agrees with that of the measurement, the residual stress in the vicinity of the weld toe will be discussed below based on the analytical results.

The surface residual stresses in the transverse direction are compression stresses in the area near the weld toe and tend to shift toward the tension stress side reaching zero as the testing point departs from the weld toe for all the testing steel plates. Figure 6 shows cross-sectional views of the typical model, which exhibits residual stress distribution. There can clearly be observed the distributions of compression stress in the steel surface area and of maximal tension stress in the vicinity of the plate

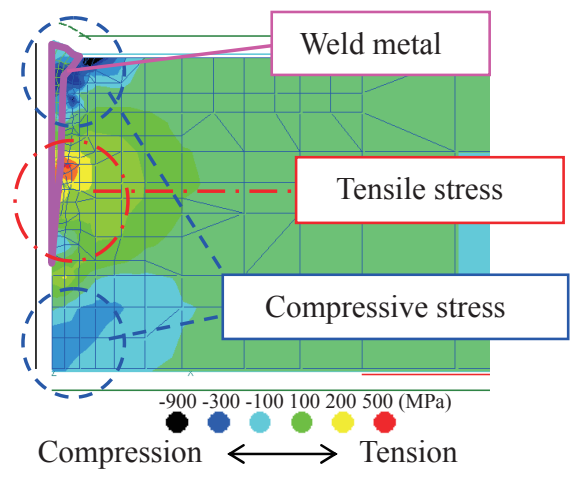

Fig. 6 Cross sectional distribution of residual stress(HT60) thickness-wise center. This agrees with the already reported experimental results ${ }^{4}$. This also has a good matching to such findings, reported for some past researches on the complete penetration weld of thick plate, that compression stress generated in the plate surface and tension stress at the midpoint of the plate thickness ${ }^{2-3)}$. The residual stress distributions described above are unique to EBW joints ${ }^{4}$. The reason for such a specific stress distribution is that the EBW process uses an electron beam of extremely high energy-density to form a weld in a very narrow zone, unlike multiple pass welding by a general arc welding process. The bead surface tends to be rapidly heated and cooled; therefore, when the high-temperature portion is cooled down to around the mechanical melting point, the maximum temperature zone will still exist around the midpoint of the plate thickness. This is presumably why the area around the midpoint of the plate thickness is cooled slower than the bead surface area, thereby generating tension stresses associated with delayed shrinkage. Also, in the weld surface area, compression stresses can be considered to generate to balance the tension stresses.

As regards the residual stress in the weld toe area that is believed to govern the fatigue strength, both experiment and analysis results exhibit compression stresses in the descending order: SCM440 $>$ S50C $>$ HT60 $>$ SUS304 $>$ SS400. This order is in accord with that by the proof stress at room temperature as shown in Fig.7.

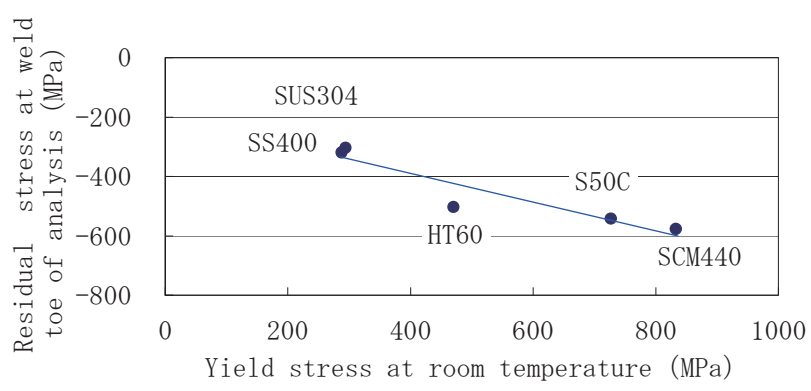

Fig. 7 Residual stress of analysis with different yield stress

These experimental results could be considered to be affected by the compression stress induced by the transformation expansion in the cooling process, but the influence of that effect was not significant in the calculation result. As stated in the first report ${ }^{4}$, the compression residual stress was induced in the weld toe area to a greater extent proportional to penetration depth as a result of the reaction of internal tensile stress (Fig. 6). In the present study, however, penetration depth was controlled almost constant with all the steel grades. The yield stress dependency can be explained such that the contribution of the compression stress relevant to the Poisson's ratio associated with the residual tension stress in the weld axis direction is significant in EBW joints with 


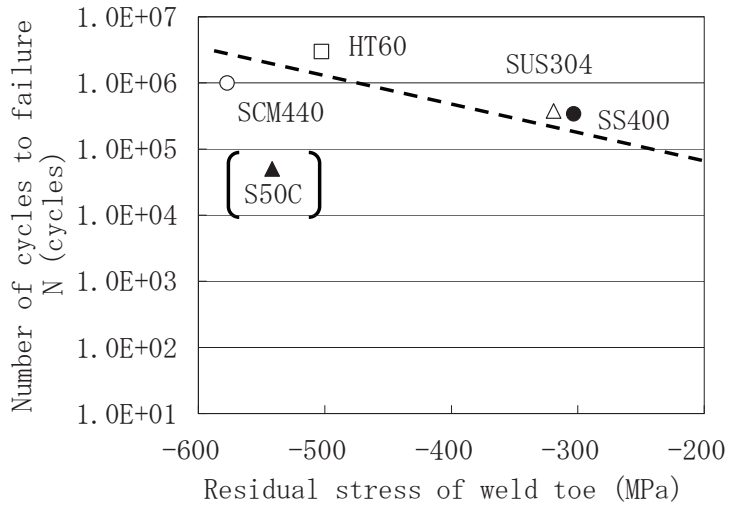

(a) Stress range $405 \mathrm{MPa}$

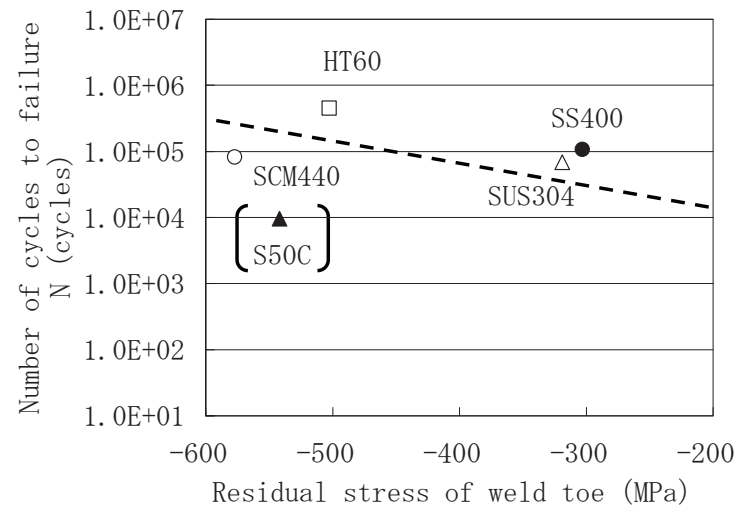

(b) Stress range $540 \mathrm{MPa}$

Fig. 8 Experimental results of fatigue tests

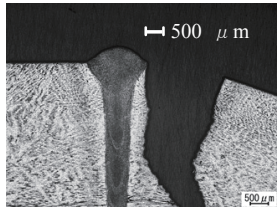

(a) SS400

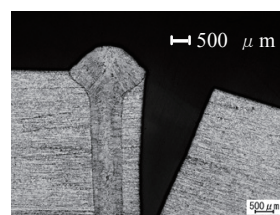

(b) SUS304

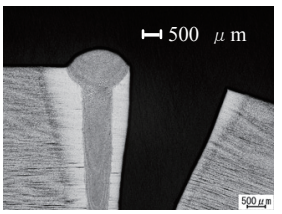

(c) HT60

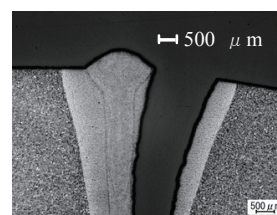

(d) $\mathrm{S} 50 \mathrm{C}$

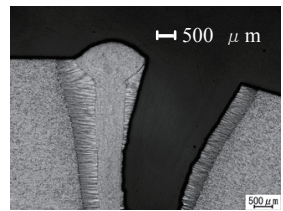

(e) SCM440

Fig. 9 Macrostructure of fatigue specimens after failure

a narrow bead width.

\subsection{Fatigue tests}

Figure 8 shows the fatigue test results. The rupture was occurred at the weld toe for all the test specimens (Fig. 9). For both test results with the stress ranges 405 and $540 \mathrm{MPa}$, such a tendency can be confirmed that the higher the residual compression stress in the weld toe area, the higher the fatigue strength for the tested steel grades except for S50C. Since fatigue rupture occurred at the weld toe for all the steel grades, the stress concentration caused by uneven shape was considered to be the reason for that tendency. However no big difference was observed in the shape of the weld toes. And then, the hardness of the weld toe and its surroundings was investigated. Vickers hardness test was carried out at approx. $0.2 \mathrm{~mm}$ below the surface of the test specimen under a testing load of $300 \mathrm{gf}$, and the test results are shown in Fig. 10. In the case of S50C which can be characterized by high quench hardenability, the weld toe and nearby area resulted in exceptionally high hardness, which should have been caused by quick heating and cooling during welding. The cause of lower fatigue life for S50C can probably be attributed to the high hardness of the weld toe and its vicinity. On the other hand, the residual stress of S50C is very similar to SS400 and SUS304 at $1 \mathrm{~mm}$ from the weld toe.This is probably because the compressive residual stress zone of S50C is narrow unlike in HT60 and SCM440 and thus, the fatigue life of S50C is short.

According to the precedent of fatigue test result that was obtained with weld joints made by EBW of medium carbon steel 6), the premature rupture was assumed to be caused by the segregated inclusions and microcracks in the finally solidified region in the weld. In the present study, however, neither inclusion nor crack could be observed by the microscopic test of the specimen. Therefore, from the present test result, it can be presumed that the remarkable hardness difference between weld and base metal increased the stress concentration and thereby reduced the fatigue strength.

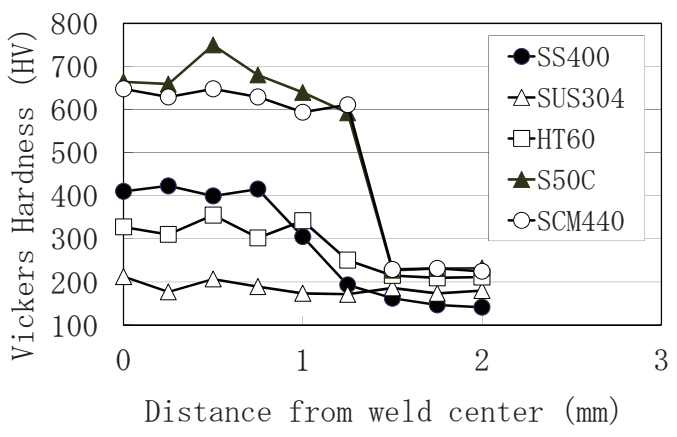

Fig. 10 Hardness distribution 


\section{Conclusions}

In this report, the authors have examined the residual stresses in EBW joints of thin steel plates as a function of steel grades. Consequently, it has been clarified that the residual stress in the weld toe area in the normal direction to the weld axis was of compression, and its degree was proportional to the yield stress at room temperature. Moreover, the fatigue properties was investigated by the three-point bending fatigue test; as a result, the fatigue characteristics of each steel grade was clarified. With respect to S50C, the hardness of the weld toe and nearby area where fatigue rupture was initiated was exceptionally high; thus, the locally hardened area could probably become the stress concentration site.

\section{Reference}

1) K. Satoh and T. Terasaki, Journal of the Japan Welding Society. 45 (1976) 560-566. (in Japanese)

2) Y. Ueda, Y.C. Kim and A.Umekuni, Quarterly Journal of the Japan Welding Society. 4 (1986) 138-142. (in Japanese)

3) K. Nakacho, H. Murakawa and T. Koide, Report of the Research Center for Ultra-High Energy-Density Heat Source. 14 (1998) 34-35. (in Japanese)

4) T. Suga, R. Kasai, T. Nagai, K. Ueno, M. Shindo and M. Mochizuki, Quarterly Journal of the Japan Welding Society. 30 (2012) 262-273. (in Japanese)

5) The Society of Materials Science, Japan : Standard Method for X-Ray Stress Measurement. (2005), 5. (in Japanese)

6) E. Abe and M. Fujisawa, Report of the TIRI. 11 (1982) 50-54. (in Japanese) 